LBNL-41679

\title{
Advanced Lighting Program Development (BG9702800)
}

\section{Final Report}

\author{
February 1998
}

\author{
Prepared for: \\ California Institute for Energy Efficiency \\ by \\ Francis Rubinstein and Steve Johnson \\ Lighting Research Group \\ Building Technologies Department \\ Environmental Energy Technologies Division \\ Earnest Orlando Lawrence Berkeley National Laboratory \\ University of California \\ 1 Cyclotron Road \\ Berkeley, CA 94720
}

The research reported here was funded, in part, by the California Institute for Energy Efficiency (CIEE), a research unit of the University of California. Publication of research results does not imply CIEE endorsement of or agreement with these findings, nor that of any CIEE sponsor. This work was also supported by the Assistant Secretary for Energy Efficiency and Renewable Energy, Office of Building Technology, State and Community Programs, Office of Building Systems of the U.S. Department of Energy under Contract No. DE-AC03-76SF00098. 


\section{Table of Contents}

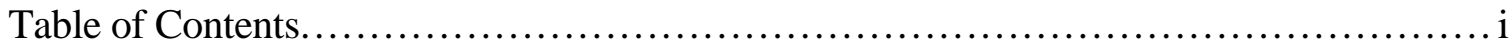

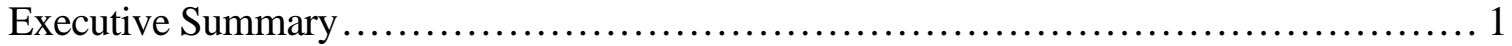

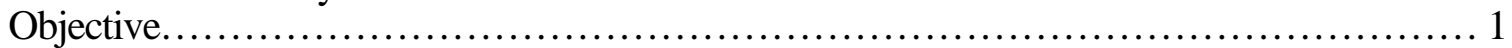

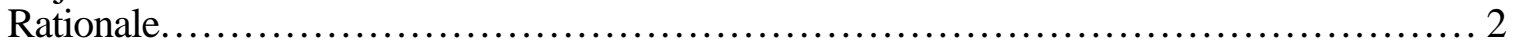

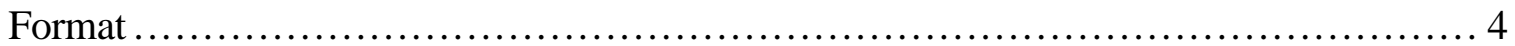

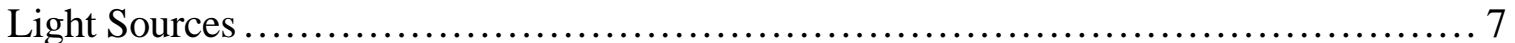

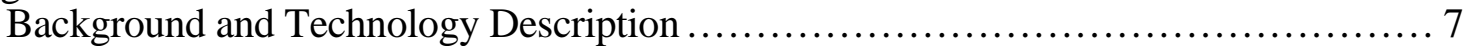

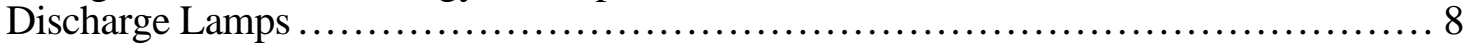

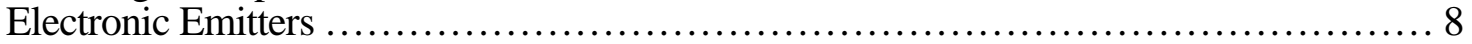

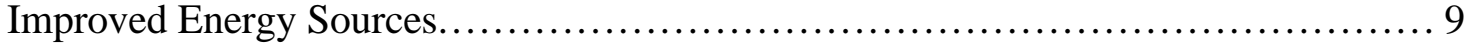

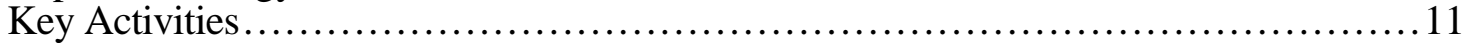

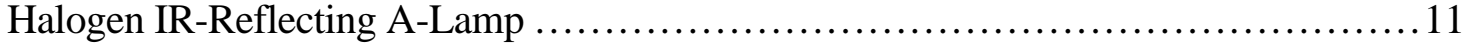

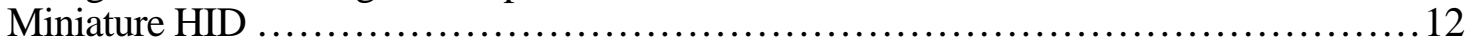

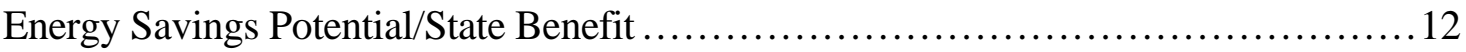

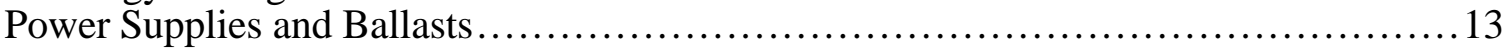

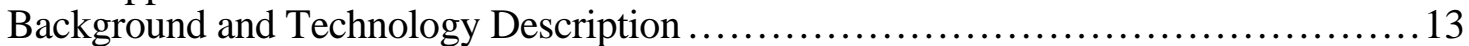

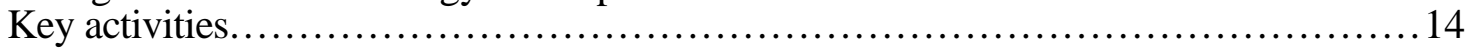

Accelerated Conversion of Magnetic to Electronic Ballast............................ 14

RD\&D in New Power Supplies for Electrodeless Sources.......................... 14

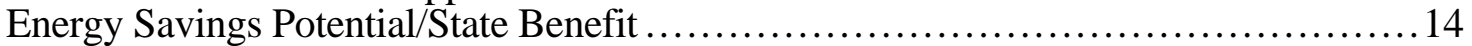

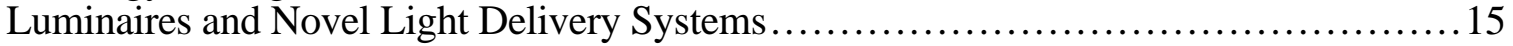

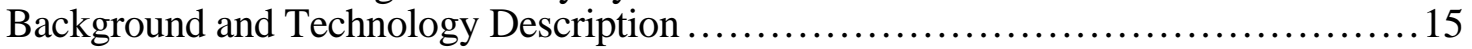

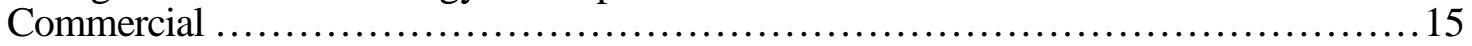

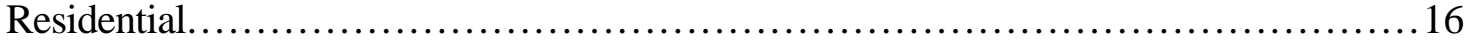

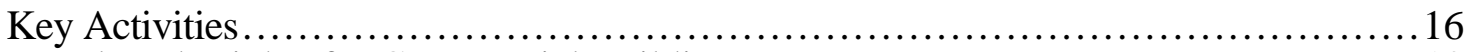

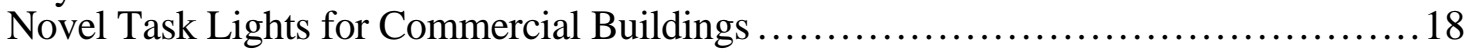

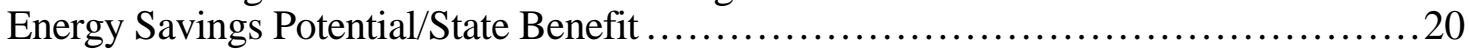

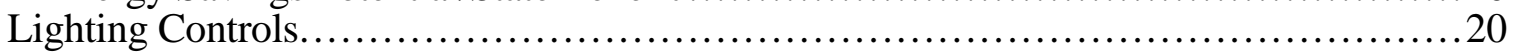

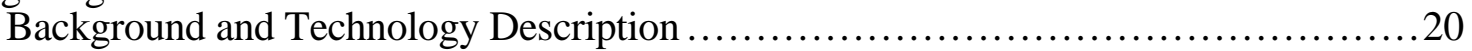

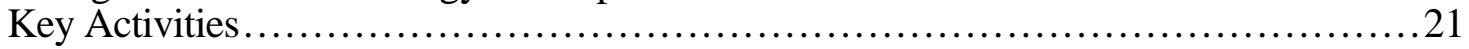

Documentation of Energy Savings and Ancillary Benefits .........................2

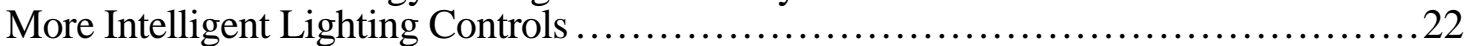

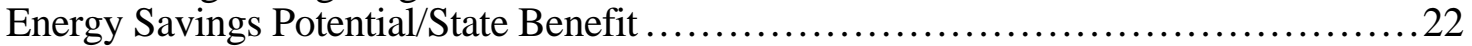

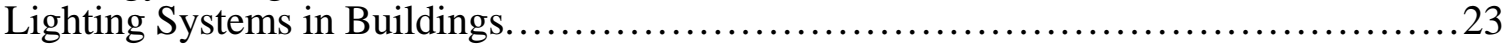

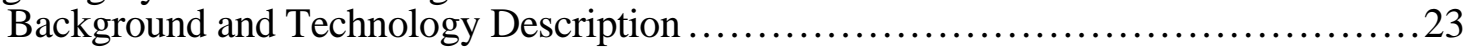

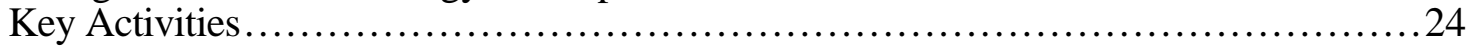

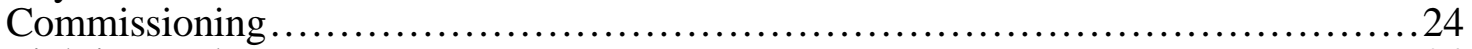

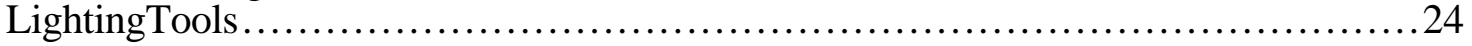

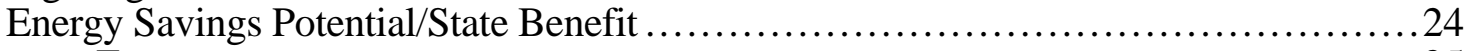

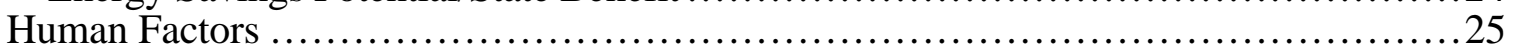

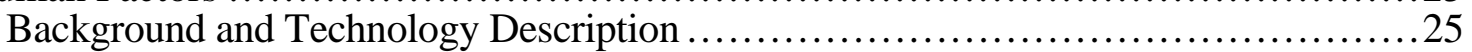

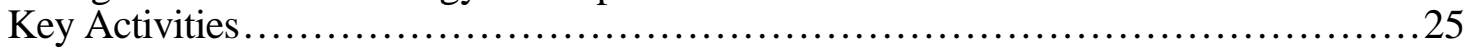

Quantification of Non-Energy Benefits of Energy Efficient Lighting ..................25

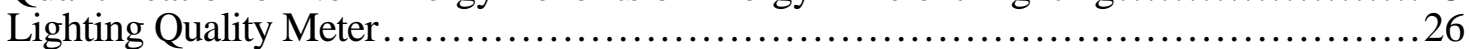

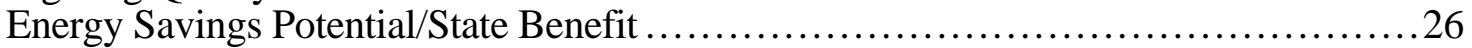

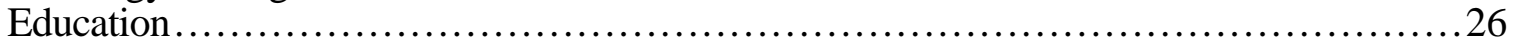

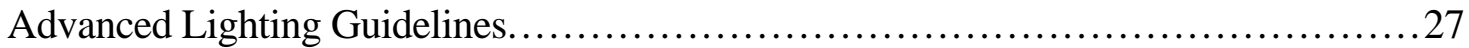

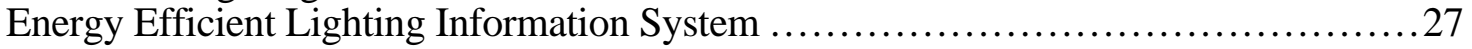

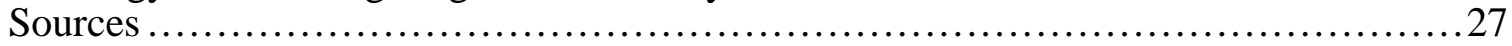

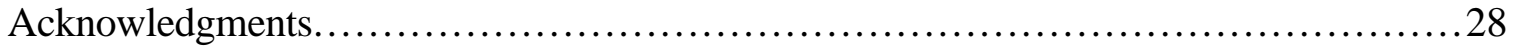




\section{Executive Summary}

The report presents a long-range plan for a broad-based, coordinated research, development and market transformation program for reducing the lighting energy intensities in commercial and residential buildings in California without compromising lighting quality.

An effective program to advance lighting energy efficiency in California must be based on an understanding that lighting is a mature field and the lighting industry has developed many specialized products that meet a wide variety of light needs for different building types. Above all else, the lighting field is diverse and there are applications for a wide range of lighting products, systems, and strategies.

Given the range of existing lighting solutions, an effective energy efficient lighting research portfolio must be broad-based and diverse to match the diversity of the lighting market itself. The belief that there is one solution — a "magic bullet," such as a better lamp, for example — that will propel lighting efficiency across all uses to new heights is, in our opinion, an illusion. A multipath program is the only effective means to raising lighting efficiency across all lighting applications in all building types.

This report presents a list of 27 lighting technologies and concepts (key activities) that could form the basis of a coordinated research and market transformation plan for significantly reducing lighting energy intensities in California buildings. The total $27 \mathrm{key}$ activities into seven broad classes as follows:

Light sources

Ballasts

Luminaires

Lighting Controls

Lighting Systems in Buildings

Human Factors

Education

Each of the above technology classes is discussed in terms of background, key activities, and the energy savings potential for the state. The report concludes that there are many possibilities for targeted research, development, and market transformation activities across all sectors of the building lighting industry. A concerted investment by the state to foster efficiency improvements in lighting systems in commercial and residential buildings would have a major positive impact on energy use and environmental quality in California.

\section{Objective}

The objective of this work is the development of a long-range plan for a broad-based, coordinated research, development and market transformation program for reducing the lighting energy intensities in commercial and residential buildings in California without compromising lighting quality. 


\section{Rationale}

Lighting energy is the largest single electrical end-use in non-residential buildings (38\% of electrical energy nationally and $42 \%$ in California) and is thought to be $10 \%$ and $28 \%$ of the electrical load in national and California residences, respectively. Given the significance of lighting as a fraction of the total electrical load in buildings as well as the cost-effectiveness of many lighting energy conservation measures (ECMs), improved lighting efficiency should logically be a major thrust of the national and state energy efficiency programs. In fact, this is not the case. For example, on the national level, the DOE's energy efficient buildings research is approximately $\$ 150$ million annually yet lighting research accounts for less than $\$ 5$ million (about 3\% of the total buildings budget). This funding is not commensurate to the relative importance of lighting energy relative to other energy-consuming systems in buildings. National lighting market transformation activities are funded at lower levels still.

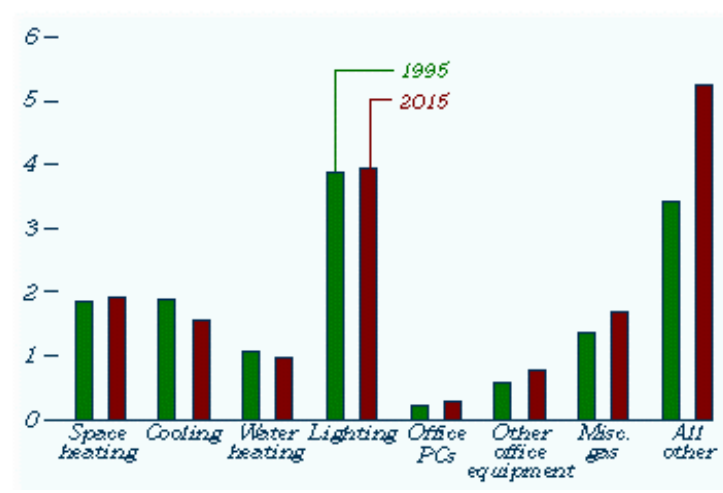

(a)

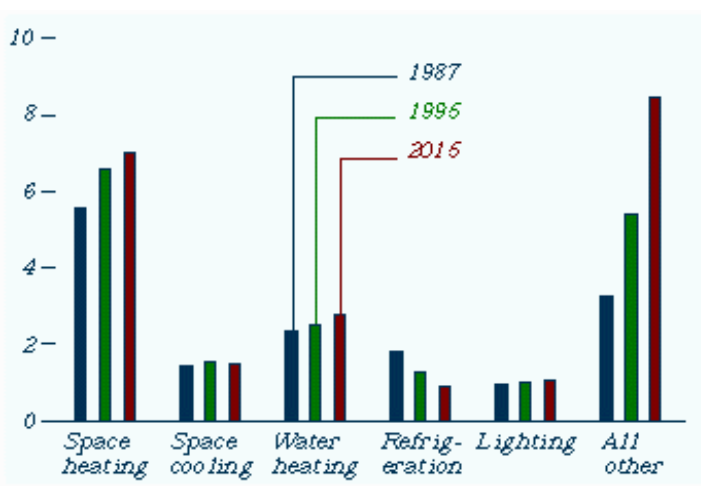

(b)

Figure 1. (a) Commercial total energy consumption by end use, 1995 and 2015 (quadrillion Btu); (b) Residential total energy consumption by end use, 1987, 1995, and 2015 (quadrillion Btu).

In California, we have the opportunity to focus new state funding on building lighting efficiency as a result of the California Assembly Bill AB 1890 which, in addition to opening up the electric industry to competition for the first time in U.S. history, allocates $\$ 64$ million annually for "public interest" energy efficiency research (PIER) as well as nearly \$250 million annually for "market transformation" activities (MT). Regulated utilities that elect to become "implementers" in this new world order are bidding for a significant portion of the MT funding and are expected to get the lion's share of the MT funds. The PIER funding, though, is more wide open. It is an objective of this report to make the case that lighting research and MT activities should capture their fair share of the energy efficiency funds.

An effective program to advance lighting energy efficiency in California must be based on an understanding that lighting is a mature field and the lighting industry has developed many specialized products that meet a wide variety of light needs for different building types. Above all else, the lighting field is diverse and there are applications for a wide range of lighting products, systems, and strategies. To accommodate this broad range of needs, the industry has developed 
many distinct types of light sources - incandescent, fluorescent, and high intensity discharge (HID is itself a family of three major lamp types) — many types of ballasts to operate them, and a bewildering assortment of fixtures for distributing the light. Layered on top of this lighting hardware are the controls for operating lighting (switches, dimmers, building EMS, etc.) and the fact that the performance of lighting systems is affected by the solar and thermal characteristics of the building. Overlaying all of these hardware and systems performance issues are the design process and building life-cycle issues that govern how (or if) architects, engineers, and lighting designers work together to create design requirements from owners needs, respond to codes and standards, integrate daylighting strategies, and then address issues surrounding the construction, commissioning, operations, and maintenance of lighting systems within the control of the total building. Finally, there are cultural and historical biases which have resulted in certain types of lighting being perfectly acceptable to occupants in one building application (say high intensity discharge lighting for commercial buildings) yet finding little acceptance in another (residential in this case).

To improve lighting efficiency, we must first understand how lighting energy is currently being used to provide lighting services in buildings. Figure 2 classifies current national lighting energy use according to light source type (fluorescent, incandescent, and HID) and according to major building type (commercial, residential, and industrial). Although this analysis is for the entire nation, it is still a fair indicator of how lighting energy is apportioned between light source and major building type at the state level.

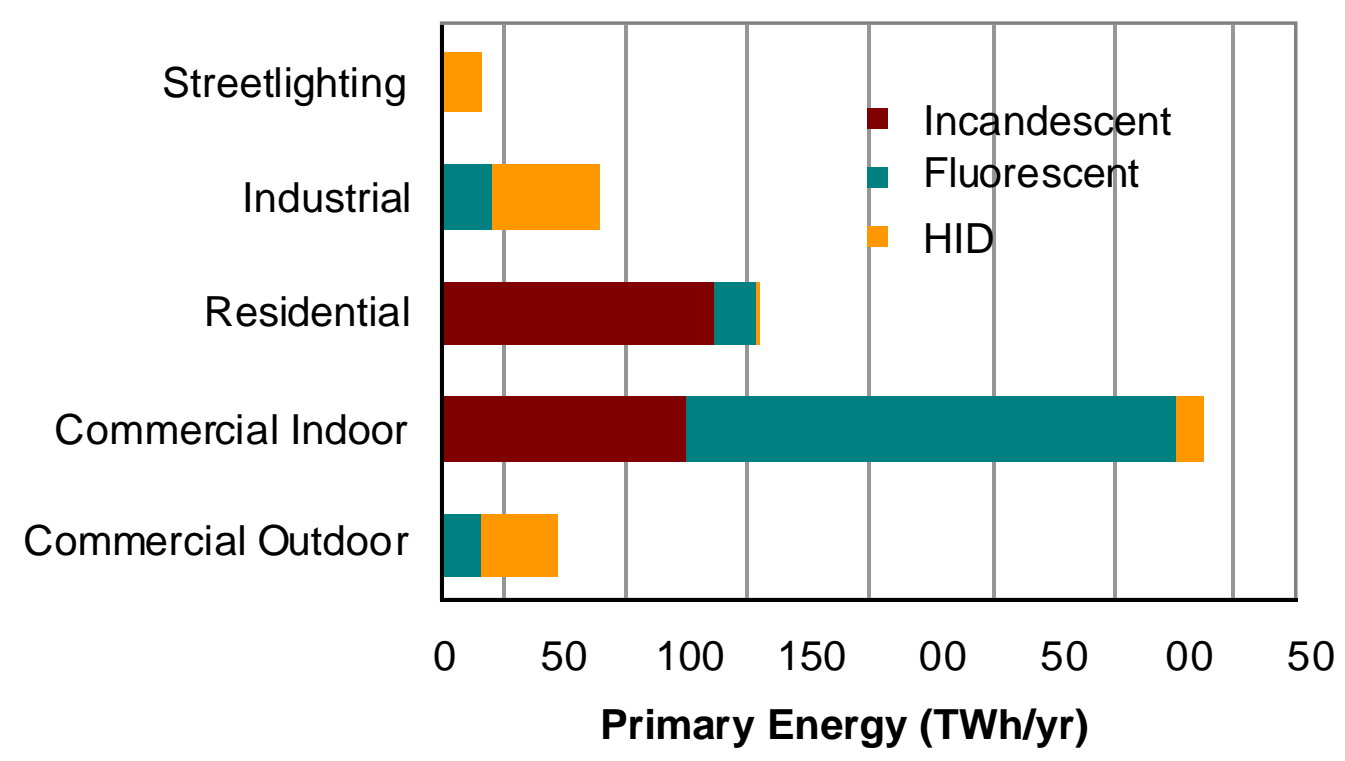

Figure 2. Lighting energy consumption by light source and building application.

It does not directly address two additional energy-related lighting issues. Electric lightingsystems have indirect energy impacts by virtue of their effect in building cooling and heating loads. Furthermore, some lighting services (e.g., daytime lighting in homes) are effectively provided by 
windows at some penalty in cooling and heating compared to insulated walls. From this analysis it follows that incandescent and fluorescent sources are responsible for the majority of all lighting energy usage and that lighting energy in all building sectors is significant. Non-building lighting loads, such as street lighting and commercial outdoor lighting, account for only $11 \%$ of the total budget. Note that almost all lighting energy in residences is due to incandescent lighting - the least efficient of all the lamp types (15-17 1/w for incandescent vs. 50-95 1/w for fluorescent and HID). To have the most effect on total lighting energy use, a lighting energy efficiency program should target commercial and residential buildings, with less emphasis on street lighting and commercial outdoor categories.

Given the range of existing lighting solutions depicted above, an effective energy efficient lighting research portfolio must be broad-based and diverse to match the diversity of the lighting market itself. The belief that there is one solution — a "magic bullet" such as a better lamp, for example - that will propel lighting efficiency across all uses to new heights is, in our opinion, an illusion. A multi-path program is the only effective means to raising lighting efficiency across all lighting applications in all building types. Of course, resources for improving lighting efficiency will always be limited, so a rational program cannot do everything and must choose its areas of focus carefully. One intent of this report, then, is to narrow down the possible areas of endeavor to a manageable number as well as to classify these topic areas according to main potential funding sources (PIER or MT).

Finally, while an effective program should be diverse, it must also be coordinated. That is, the different elements of a successful energy efficiency program should be complementary to avoid sending confusing market signals about which technology or approach is appropriate for which application.

\section{Format}

This report presents a list of 27 lighting technologies and concepts (key activities) that could form the basis of a coordinated research and market transformation plan for significantly reducing lighting energy intensities in California buildings. Many of these key activities were identified in the LBNL Strategic Plan for Lighting Research. The Strategic Plan represents a national plan based on an assessment of the existing U.S. market conditions and needs as well as an understanding of the level of development of the different technologies and concepts. Many of the technologies described in the Plan are also appropriate when applied at the state level. We have divided the total 27 key activities into seven broad classes as follows:

1. Light Sources

- Discharges

- Material science

- Incandescent lamp replacements

2. Power supplies/ballasts

3. Luminaires and novel light delivery systems

4. Lighting controls

5. Lighting systems in buildings

6. Human factors

7. Education (Outreach) 
In the light sources category, it is convenient to divide the field into engineering subclasses as indicated above. For the other technology categories it is more convenient to subdivide according to major building application (commercial and industrial or residential) to match the technology to the end-use category about which we have some energy use data.

Within each subclass, the technologies have been further classified according to whether their development is primarily a market transformation activity or whether they require near, mid- or long-term research to be brought to the point of commercial viability. There are crosscutting issues, such as codes and standards, related to lighting technologies and systems and to whole buildings; they are discussed within each of the eight sections. Since the available funding to come from AB1890 is split between "public-interest RD\&D" and "market transformation," a clear definition of both is useful. We provide below a traditional, and somewhat simplistic, set of definitions of these two sets of activities. As one begins to explain the details of suggestible problems, it is apparent that the most effective programs may utilize combinations of both types of activities.

Research, Development, and Demonstration $(R D \& D)$ : In RD\&D, technology advancement usually starts with basic, then applied research, followed by product development and demonstration. The technologies that stem from RD\&D, though, are not always adopted in the market and in many cases, more advanced efficient technologies remain on the shelf for ten or more years before being adopted (if at all).

Market Transformation: For a detailed definition of market transformation, the reader is referred to [Eto et al 1996]. For an excellent background on implementing market transformation see [Nilsson 1995]. For the purposes of this report, though, market transformation starts up where the demonstration part of RD\&D leaves off. Market transformation occurs by 1) pre-introducing products into the market place, 2) accelerating their penetration into the market, and 3) enlarging market share. A state-based market transformation program should focus primarily on the first two activities leaving it to the self-interest of the manufacturers to enlarge market share. In short, market transformation activities are not aimed at researching and developing new efficient products and concepts, but rather at opening up the lighting market to promote the acceptance for new products that are already commercially available in some form, or nearing commercial availability but are not widely adopted.

There is conceptually some overlap between the two categories (RD\&D and MT) but as the funding for these two categories would come from different sources, it is useful to classify each technology in one category or the other while noting if there is an overlap. In fact, market barriers might be addressed in a MT program element conducting research to determine why a particular technology is not accepted in the marketplace, or completing short term engineering $R \& D$ to remove a technical obstacle blocking large-scale market introduction.

The matrix of technologies, exclusive of the education topic area (which is in a class by itself, classified according to the above scheme) is given in Table 1. 
Table 1. Key Lighting Activity Matrix

\begin{tabular}{|c|c|c|c|c|c|}
\hline $\begin{array}{l}\text { Technolog } \\
\text { Category }\end{array}$ & Subclass & $\begin{array}{c}\text { Market } \\
\text { Transformation }\end{array}$ & $\begin{array}{l}\text { Near Term } \\
(1-3 \quad y r)\end{array}$ & $\begin{array}{l}\text { Mid Term } \\
(3-6 \quad y r)\end{array}$ & $\begin{array}{c}\text { Long Term } \\
(>6 \quad y r)\end{array}$ \\
\hline \multirow[t]{4}{*}{$\begin{array}{l}\text { Light } \\
\text { Sources }\end{array}$} & Discharges & & & $\begin{array}{l}\text { Low power } \\
\text { HID (w/and } \\
\text { w/o } \\
\text { electrodes) }\end{array}$ & $\begin{array}{l}\text { Molecular } \\
\text { radiators } \sim 200 \\
1 / \mathrm{w}\end{array}$ \\
\hline & $\begin{array}{l}\text { Electronic } \\
\text { Materials }\end{array}$ & $\begin{array}{l}\text { Convert } \\
\text { incandescent exit } \\
\text { signs to LED }\end{array}$ & $\begin{array}{l}\text { LEDs } \\
\text { (especially } \\
\text { traffic light } \\
\text { conversion) } \\
\end{array}$ & & $\begin{array}{l}\text { High efficiency } \\
\text { solid-state } \\
\text { devices }\end{array}$ \\
\hline & & & & & $\begin{array}{l}\text { Two photon } \\
\text { phosphor }\end{array}$ \\
\hline & $\begin{array}{l}\text { Incandescent } \\
\text { Lamp } \\
\text { Replacements }\end{array}$ & $\begin{array}{l}\text { Halogen IR } \\
\text { replacement for } \\
\text { incandescents }\end{array}$ & & $\begin{array}{l}\text { Mini HID } \\
\text { (reflectorized } \\
\text { \& A-lamp } \\
\text { replacement) }\end{array}$ & \\
\hline $\begin{array}{l}\text { Power } \\
\text { Supplies/ } \\
\text { Ballasts }\end{array}$ & & & $\begin{array}{l}\text { Improved } \\
\text { efficiency of } \\
\text { dimming } \\
\text { ballasts } \\
\end{array}$ & & $\begin{array}{l}\text { Component } \\
\text { improvements } \\
\text { for electrodeless } \\
\text { power sources }\end{array}$ \\
\hline \multirow{3}{*}{$\begin{array}{l}\text { Luminaire } \\
\text { and Novel } \\
\text { Light } \\
\text { Delivery } \\
\text { Systems } \\
\end{array}$} & $\begin{array}{l}\text { Commercial and } \\
\text { Industrial }\end{array}$ & $\begin{array}{l}\text { Troffer to } \\
\text { direct/indirect } \\
\text { fixture conversion }\end{array}$ & $\begin{array}{l}\text { Indirect } \\
\text { lighting } \\
\text { using HID } \\
\text { sources }\end{array}$ & $\begin{array}{l}\text { General } \\
\text { application of } \\
\text { light guides }\end{array}$ & \\
\hline & Commercial & $\begin{array}{l}\text { Better task and } \\
\text { furniture-based } \\
\text { lighting }\end{array}$ & $\begin{array}{l}\text { Luminaires } \\
\text { for } \\
\text { inductively- } \\
\text { coupled } \\
\text { fluorescent } \\
\text { sources } \\
\end{array}$ & $\begin{array}{l}\text { Improved } \\
\text { streetlights }\end{array}$ & \\
\hline & Residential & $\begin{array}{l}\text { CFL-based } \\
\text { dedicated fixtures }\end{array}$ & & & \\
\hline $\begin{array}{l}\text { Lighting } \\
\text { Controls }\end{array}$ & Commercial & $\begin{array}{l}\text { Assess performance } \\
\text { of existing controls }\end{array}$ & $\begin{array}{l}\text { Improved } \\
\text { sensors, } \\
\text { algorithms } \\
\end{array}$ & $\begin{array}{l}\text { Development } \\
\text { of intelligent } \\
\text { controls } \\
\end{array}$ & \\
\hline $\begin{array}{l}\text { Lighting } \\
\text { Systems in } \\
\text { buildings }\end{array}$ & Commercial & & $\begin{array}{l}\text { Remote } \\
\text { building } \\
\text { operation } \\
\text { and control; } \\
\text { design tools } \\
\end{array}$ & $\begin{array}{l}\text { Integration of } \\
\text { lighting, } \\
\text { envelope and } \\
\text { HVAC }\end{array}$ & \\
\hline $\begin{array}{l}\text { Human } \\
\text { factors }\end{array}$ & $\begin{array}{l}\text { Commercial and } \\
\text { Industrial }\end{array}$ & & $\begin{array}{l}\text { Tools to } \\
\text { assess } \\
\text { lighting } \\
\text { quality }\end{array}$ & $\begin{array}{l}\text { Productivity } \\
\text { studies in lab } \\
\text { and field }\end{array}$ & \\
\hline Daylighting & Commercial & Improved Tools & $\begin{array}{l}\text { Advanced } \\
\text { Tools }\end{array}$ & $\begin{array}{l}\text { Integrated } \\
\text { Control } \\
\text { Systems }\end{array}$ & $\begin{array}{l}\text { Smart glazing } \\
\text { systems, } \\
\text { Advanced Optical } \\
\text { Materials } \\
\end{array}$ \\
\hline
\end{tabular}


The remainder of this report presents an analysis of each of the major lighting topics shown in the matrix according to the following format:

1. Background and Description

In this section the background of the major topic is presented in terms of its context and significance in commercial and residential buildings. The section also contains brief descriptions of the underlying technologies or concepts.

2. Key Activities

The specific technologies and concepts proposed in this report are listed here as key activities. In this section, we identify whether the activity should most appropriately be funded from the PIER funding or MT.

3. Energy Savings Potential/State Benefit

In this section, we estimate the energy savings potential for the major topic category based on our knowledge of the current and projected future efficiencies and potential applicability in California buildings. In some cases, we have drilled down the major category to estimate the energy saving potential at the key activity level. In this section, we include the benefits to the state for funding the key activities including environmental benefits, energy cost reductions for California consumers, potential for starting new California industries or services to foster energy efficient lighting products and services, and jobs added within the state. In estimating energy savings potential for California, we often use $10 \%$ of nationally derived estimates, which is roughly proportional to California's population relative to the entire U.S. Environmental impacts are calculated based on the energy savings potential. A one TW-hr reduction in primary lighting energy equates to a reduction of .65 million metric tons of emitted $\mathrm{CO}_{2}$.

\section{Light Sources}

\section{Background and Technology Description}

In their efforts to increase light source efficacy, the major U.S. lamp companies (General Electric, Osram-Sylvania, and Philips Lighting) have historically invested considerable research into understanding both low- and high- pressure discharges as incorporated into today's fluorescent and HID sources ${ }^{1}$. Advances in the field of materials sciences have resulted in a family of semiconductor devices that can serve as directional, low-output, light sources. Even incremental improvements to the venerable incandescent lamp are being researched and some new incandescent lamp families (most notably the Halogen Infrared Reflecting-HIR_lamp) have resulted from these efforts.

\footnotetext{
${ }^{1}$ An excellent background to the physics and engineering of advanced light sources is found in the proceedings of the 1995 ALITE conference [ref. 13].
} 


\section{Discharge Lamps}

Conversion Efficiency Phosphor. Research efforts have focused principally on atomic line emitters in which, in the case of the fluorescent lamp, the discharge excites the phosphor with ultraviolet light. The phosphor subsequently fluoresces in the visible spectrum, consequently losing one-half of the original UV photon energy in the process. The opportunity for improvement in the efficiency of this type of lamp is two-fold: either increase the number of photons from the phosphor per ultraviolet photon (so-called "two-photon" phosphor), or excite the phosphor with a lower energy photon. Unlike the fluorescent lamp, the discharge in a HID lamp is the source of the visible light. Research continues in these discharges to find additives that will improve color properties of the source and efficiency.

Electrodeless Discharge (including Fluorescent and HID. The chemical composition of both fluorescent and HID discharges is limited by the chemical activity of the discharge elements with the envelope and especially, the electrodes. With the continued development of more efficient and compact radio frequency and microwave sources, the chemical limitation of the electrode is being removed, opening the doors to a whole new set of compounds. The principle is the same: to use the discharge to emit visible light. However, the attention is on molecular rather than atomic radiators.

Molecular Radiators. Molecular radiators have the potential to reduce the prevalent energy loss mechanisms in the plasma. Radiating in the broad continuum similar to an incandescent lamp, they have a theoretical limit of close to 200 lumens per watt with a high color rendering spectrum, double the efficiency of most fluorescent and HID sources. The sulfur lamp is an example of a molecular radiator with a discharge efficiency equal to fluorescent and HID. Developing electrodeless molecular discharges is long-term exploratory research, but it has a large potential return on investment.

Very low power HID. Another vital focus of work would be molecular discharges that are chemically inactive with electrodes. These discharges are achieved by increasing the pressure of current HID sources by significantly reducing the discharge volume, and by proportionately increasing the thickness of the envelope. The resulting HID sources will have lower wattages, in the range of 1 to 35 watts, and a high efficiency, and will be small in size, providing a competitive point-source alternative to the incandescent lamp. Source development to the stage of pilot production would take three to five years and is relatively low risk because experimental prototypes have been demonstrated successfully.

\section{Electronic Emitters}

Technologies developed in the semiconductor industry will play an increasingly significant role in the development of future light sources. Semiconductor technology has already been used in sources such as light-emitting diodes (LED). Research programs are underway to develop more efficient blue and green gallium nitride LEDs to complement the recently improved red LED. Once the full complement of LEDs is developed, this source will appear in many more applications. The red LEDs are finding widespread use replacing incandescent traffic lights. Here, a 150-Watt incandescent source is replaced with an 18-Watt LED display. The energy savings per light source is quite significant. Red LEDs have also been incorporated in exit signs where they have the 
advantage of significantly lowering energy consumption as well as being longer lived than the incandescent lamps they replace. Interestingly, the efficacy of LEDs is currently no better than the incandescent lamp. The energy savings from LEDs stems from the directional focusing ability of the LED, demonstrating that efficiencies can be achieved in certain applications with equivalent or even less efficient sources but with unique optical properties.

In the future, semiconductor technology could have an impact on the lighting industry in the development of new processes. Using semiconductor technology, manufacturers could construct microstructures, thin films, and multi-layer depositions. Specific applications include new types of electrodes, improved glass seals, and protective barriers to various lamp components. Improved electrode construction could decrease power dissipated in the electrode, increase lamp life, and decrease the rate of lamp depreciation. Deposition technologies could lead to new processes in forming glass seals with other types of glass and metal parts, improving reliability and reducing cost. They can also be used to form protective thin films over various components to improve maintenance, increase life and reliability, and decrease the material costs. These are exploratory, long-term research programs.

\section{Improved Energy Sources}

Incandescent sources consume $37 \%$ of commercial lighting energy and nearly $90 \%$ of residential lighting. Commercially available halogen lamps with infrared reflecting coatings embody a technology that could serve as the basis for producing a more efficient general service incandescent lamp that could physically fit in the vast majority of the existing (Edison) sockets. The target market for this product should be low-use sockets as indicated in the analysis below. High use sockets should be the focus of a complimentary effort to accelerate the introduction of dedicated CFL fixtures.

In Figure 3, the distributions of household lighting sockets and energy consumption by hours of use are illustrated ${ }^{2}$.

\footnotetext{
${ }^{2}$ Adapted from [Vorsatz et al. 1997].
} 


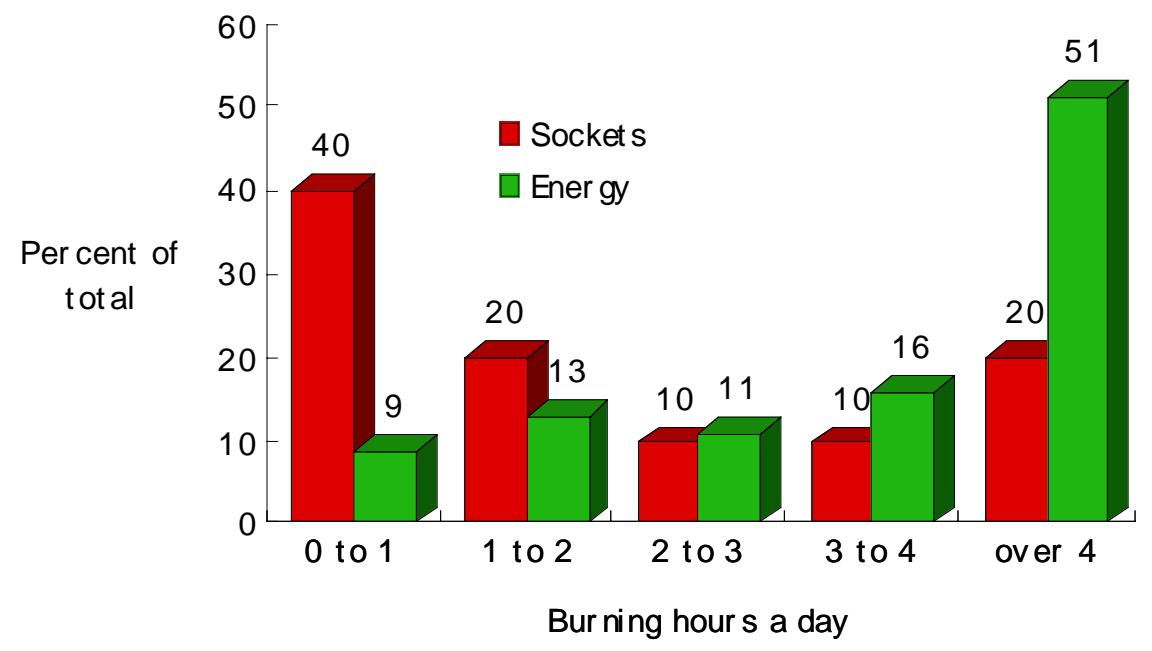

Figure 3. Residential lighting energy by burning hours.

From these data, it appears that lighting energy usage in residences can be divided into two categories of fixture operation:

Low-use sockets represent $70 \%$ of the sockets in the home and are used for less than three hours each day, accounting for 33\% of all household lighting energy.

High-use sockets operate for three or more hours a day consume $67 \%$ of all lighting energy in household and represent only $30 \%$ of the total number of sockets.

These two usage patterns suggest that the residential lighting market should be viewed as two distinct sub-markets, with a different strategy to reduce the energy consumption in each.

For short burning hour sockets, a low-cost, moderately efficient source, such as the halogen infrared (HIR) lamp is the preferred source. If this lamp could be manufactured and sold at \$34/lamp, it could be a universal cost-effective replacement for the standard incandescent lamp. The HIR lamp would be $25 \%$ more efficient than a standard incandescent lamp and have three times the useful life. An aggressive program to stimulate introduction of the HIR product sooner has the potential to rapidly reduce lighting loads in residential and commercial buildings.

The conversion of high-use sockets to CFL lighting is discussed in the Lighting Distribution section. 


\section{Key Activities}

\section{Advanced Light Source Research}

Although lamps are currently produced by non-California companies, there is the opportunity for California-based universities, national labs, and private sector industry to play a role in the basic research that would lead to the development and eventual commercialization of much more efficient light sources with efficacies approaching those of the theoretical maximum (about 200 1/w for white light). With funding from the state and potential partnerships with lamp industry, California universities and motivated private companies could lead the nation in pursuing the basic precompetitive research that might, for example, lead to a "two-photon" phosphor that could improve the efficiency of all fluorescent lamps. Similar advances are possible in molecular emitters, exotic gases for electrodeless HID sources, and semi-conductor-based lighting (such as LEDs). As the home of the electronics industry, based on semi-conductor materials and manufacturing technologies, California could help accelerate a transition to a new generation of efficient lighting technology. Solving any of these key light source issues would have major implications to the lighting industry and would substantially reduce lighting energy use. A "Grand Lighting Challenge" consortium devoted to tapping the enormous intellectual capital of the California University system and the National Labs to solving key engineering problems facing the lamp industry could be launched with judicious use of PIER funding. This is high risk, high potential reward R\&D activity.

\section{Halogen IR-Reflecting A-Lamp}

Heschong 1997] recommends that the CEC explore the concept of a drop-in replacement for the Aline incandescent lamp based on the HIR technology. Such a lamp would have all the favorable attributes of incandescent lighting but with higher efficacy, long life and relatively low-cost.

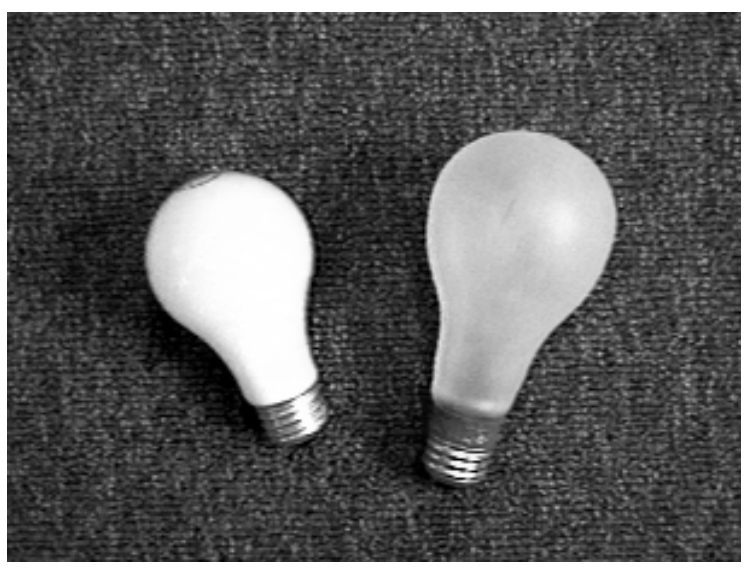

Figure 4. An HIR lamp prototype (right) constructed at LBNL is shown next to a standard incandescent lamp. An HIR lamp that was $30 \%$ more efficient and had three times the life would be a cost-effective alternative to the standard incandescent if it was under $\$ 4 /$ lamp.

The DOD, through the Defense Logistic Agency, has offered two RFPs requesting bids from manufacturers for more efficient A-lamps but have received no bids to date. In addition, the International Energy Agency recently issued a request for tenders for lamps with similar technical properties and price point as the DOD solicitation, but for a European product [Rubinstein 1996]. 
So far, no manufacturers have responded with serious bids but there is evidence that a more positive response could be obtained if the manufacturer incentive (i.e., the volume of lamps purchased) were larger. Discussions with manufacturers suggest that they are capable of and willing to make the lamp, but are reluctant to invest in the necessary specialized manufacturing equipment until there is a proven need. An aggressive program to transform the market through educating and providing targeted incentives for consumers would help motivate the lighting industry to manufacture this technology.

The timing is excellent for California to join these ongoing activities through a market transformation program aimed at assembling sufficient buyers in the private sector as well as with state government agencies to increase the potential buying pool. A significantly increased buyer's pool within the large California market could provide sufficient enticement for at least one large lamp manufacturer to agree to produce the more efficient lamps with the requisite efficiency, lifetime, and cost to be cost-effective to the consumer relative to standard incandescent lamps. A cost-effective price for a 3000 hour HIR lamp (60-100 watt equivalent) with an efficacy of 21-22 1/w is between $\$ 3-4 /$ lamp for typical operating hours and energy prices.

No R\&D is required because basic HIR technology already exists on the market (for example, GE's HIR PAR-lamp). The activity is therefore mostly market transformation although a number of market conditioning and educational activities would have to accompany the release of new lamp and ensure that it was clearly labeled to foster appropriate use.

\section{Miniature HID}

Even with more efficient halogen and HIR PAR lamps being specified in residential and commercial applications, an efficient focused light source (for example in a reflectorized or PARlamp configuration) would have good application potential for directional beam lamps for commercial and residential application if the price was low enough. (CFLs don't work for this application because of their extended source size and subsequent low luminosity.)

It may be possible to apply semiconductor process technology to the business of creating new light sources, especially miniaturized HID sources of low power (15 - 30 watts). Because of the close proximity of Silicon Valley, the prospect of producing efficient lamps in the state has tantalizing job creation possibilities.

\section{Energy Savings Potential/State Benefit}

Estimating the energy savings benefits to the state for embarking on each of the above activities is difficult because we don't know with any precision how much each of these technologies, if brought to commercialization, could save relative to the existing products that they would supplant. However, one can get a rough estimate of the energy savings potential for some of the more promising approaches.

With regards to the research on discharge lamps, a two-photon phosphor, for example, would have enormous energy savings implications because of the relatively large improvements in efficacy if such an approach is successful as well as the very wide use of fluorescent lighting in the commercial building sector. We estimate that a two-photon phosphor could reduce California 
lighting energy use by about $9 \mathrm{TWh} / \mathrm{yr}$ (10\% of $87 \mathrm{TWh} / \mathrm{yr}$ estimated nationally). Note that this is long-term research and should be considered high risk.

With respect to research on materials sciences, one can get an estimate of the energy savings potential of new solid-state devices for lighting purposes by examining the replacement of incandescent lamps with LEDs in exit signs. According to [Conway and Boyce 1997], there are 100 million exit signs in the U.S. (approximately 10 million in California) and it is reasonable to assume that they operate for 24 hours/day. However, there is little data on the distribution of wattages across the national inventory of exit signs, so one must estimate this before estimating the potential energy savings of converting from incandescent to LED technology. From [ref 19], we assume that $70 \%$ of the in-place stock is incandescent (using an average of 30 watts/exit sign) and the remaining 30\% energy-efficient (either CFL or LED, primarily). The national energy consumption due to exit signs is therefore about 21 Twh/yr (70\% of 100 million units @ 30 watts/unit x $8760 \mathrm{hr} / \mathrm{yr}+30 \%$ of 100 million units @ 10 watts/unit x $8750 \mathrm{hr} / \mathrm{yr}=21 \mathrm{Twh} / \mathrm{yr}$ ). If the in-place stock of incandescent exit signs were replaced with LED exit signs using an average of only about 7 watts each, the national energy savings would be $14 \mathrm{TWh} / \mathrm{yr}$. The savings potential in California for replacing incandescent exit signs with LED signs is therefore approximately 1.4 TWh/yr.

To estimate the energy savings potential of replacing standard incandescent lamps with HIR-based A-lamps, we take $15 \mathrm{l} / \mathrm{w}$ for the 60 watt standard lamp efficacy and $21 \mathrm{l} / \mathrm{w}$ for the assumed efficacy of a practical (i.e., inexpensive) HIR-based A-lamp. This provides a power reduction of about $25 \%$ without a lowering of light levels. We assume that $90 \%$ of the incandescent lighting in residential buildings can be replaced with the HIR technology. This results in energy savings of 3.2 TWh/yr for California residences. A similar magnitude of energy savings is achievable in the commercial building sector where, because of the longer burning hours, virtually all incandescents could be economically replaced with HIR lamps.

California residences also use more lighting energy than the national average making a drop-in replacement a high priority California issue.

\section{Power Supplies and Ballasts}

\section{Background and Technology Description}

In the last decade, electronic ballasts in the commercial marketplace have had a great impact on the lighting industry. Combined with more efficient T-8 fluorescent lamps, this technology has realized a large energy savings. California's Title 24 has helped to drive the commercial building market to electronic ballasts and sales of electronic ballasts now account for about $30 \%$ of all ballast sales in the U.S. The ratio is probably even higher in California. The electronic ballast will continue to play a major role in saving energy as it evolves with added controllability features.

Research and development in new power sources focuses on improvement in the efficiency, size, and life of high-frequency power supplies that will operate electrodeless discharge sources. The development of these power sources is closely tied to that of new discharge lamps described above in "discharge light sources." It is critical to bring these high-frequency power sources to the efficiency, reliability, and cost standards characteristic of the current electronic ballast. This is a 
long-term goal and will require investment in all phases of research, from development of new components to demonstration and application studies.

\section{Key activities}

\section{Accelerated Conversion of Magnetic to Electronic Ballast}

Given that electronic ballasts have become a mainstream technology in California, it is not unreasonable to assume that there are monetary incentives (tax credits, etc.) as well as regulatory means that, if properly applied, could significantly accelerate the replacement of magnetic ballasts with electronic ballasts in California buildings. This is largely a market transformation activity that does not require $R \& D$.

\section{Improved Dimming Electronic Ballasts}

Dimming ballasts represent an enabling technology that allows expanded implementation of many lighting controls strategies such as daylight harvesting, manual dimming control, and ability to respond to real-time utility price signals. The current crop of dimming ballasts can be improved both in terms of their efficacy at full power (compared to that of a comparable non-dimming electronic ballast) and their loss in efficacy with dimming. In addition, a dimming electronic ballast that can be reliably controlled directly over the switchleg wiring, without the need for a separate low voltage loop, could be widely applied to existing commercial and residential spaces.

\section{RD\&D in New Power Supplies for Electrodeless Sources}

Applied R\&D in the area of improved power supplies for electrodeless sources could lead to new industries in the state as well as improved efficiency for energy consumers. Given the strength of California companies in the semiconductor industry, it is reasonable that R\&D be pursued to using these industrial capabilities to produce new electronic products that use energy more sparingly than conventional power supplies.

\section{Energy Savings Potential/State Benefit}

To estimate the energy savings potential of accelerating the replacement of fluorescent magnetic ballasts with electronic ballasts and T-8 lamps, we estimate that the average lamp/ballast system efficacy for the in-place fluorescent lighting market is $661 / \mathrm{w}^{3}$. To estimate the energy saving potential of converting most of the remaining stock to the T-8 technology, we assume that approximately $75 \%$ of the stock that hasn't upgraded to T-8 lamps could do so economically. If T8 lamps and electronic ballasts were to be applied to the commercial fluorescent lighting stock, the fluorescent lighting energy budget for California would drop from 18.9 billion $\mathrm{kW}$-hr to 15.9 billion $\mathrm{kW}-\mathrm{hr} / \mathrm{yr}$ (a 16\% savings) without reducing light levels. It would result in an energy savings of three billion $\mathrm{kW}-\mathrm{hr} / \mathrm{yr}$.

\footnotetext{
${ }^{3}$ Assumes that $90 \%$ of the in-place stock uses T-12 lamps and magnetic ballasts averaging $641 / \mathrm{w}$ and the remaining $10 \%$ of the stock uses T-8 lamps and electronic ballast averaging $87 \mathrm{l} / \mathrm{w}$.
} 


\title{
Luminaires and Novel Light Delivery Systems
}

\author{
Background and Technology Description
}

\section{Commercial}

New light sources are introduced into the market faster than luminaire manufacturers can design fixtures for them. For example, a recent innovation is the inductively-coupled fluorescent source with four times the life of conventional electroded fluorescent lamps and $10 \%$ higher efficiency. These light sources do not have the starting limitations of electroded lamps and could be cycled frequently and used in more extreme temperature environments without damaging the source. The technology is so new that no luminaires exist for it at present. Because of its unique shape, existing luminaires cannot be easily modified to accept its geometry. Application of this new source will require developing a new light delivery system.

Inductively-coupled lamps could be a more efficient white-light alternative to high-pressure sodium and HID sources for some outdoor applications. To stimulate the introduction of the product as an energy-efficient "white light" alternative to street lighting, CEC could fund an application study with lamp manufacturers, luminaire manufacturers, and municipalities as partners to demonstrate the technology's benefits.

Fiber optics and light pipes or guides continue to present an opportunity to distribute light in specific applications. One application with the potential for significant impact on the energyefficiency of an entire type of facility is in cleanroom environments, which are particularly common in the Silicon Valley area. Cleanrooms handle large volumes of temperature-controlled air. Removing heat generated by the lamp and ballast from the cleanroom environment significantly reduces the power loading on the air handling system. Light sources, power supplies, and light pipes are available for an application study to demonstrate this technology.

Within the commercial office space, control of light distribution and intensity are critical factors in providing adequate lighting in the workspace. Indirect lighting is increasingly popular for distributing low or no-glare light. Costs can be decreased and efficiency increased by reducing the number of fixtures with a smaller number of higher powered sources. Development and analysis of these indirect systems could lead to a more efficient use of energy while maintaining or improving the lighting quality of the workspace. An element critical to developing indirect lighting for general illumination of the workspace is controllable light sources at the employee work space. The task light is the most prevalent controllable light source in the workspace.

Technology is available that provides flexibility in the location of the task source in all three dimensions and in the intensity of the light. However, no source is available which effectively modifies the distribution of the light. With holographic, thin-film lenses, it is possible to change the light distribution of these sources as required by the task. This would have the effect of reducing energy requirements within the workspace while potentially improving the performance of the employee. 


\section{Residential}

As described in the light source section, a few luminaires in residences are on for long periods of time while the majority of fixtures burn for less than three hours/day. In California kitchens, full size (4 ft) fluorescent lighting is commonly used for these longburning-hour applications because Title 24 requires that general lighting in kitchens be fluorescent, and compliance appears high. For outdoor fixtures and rooms such as the living room and the den, which also have relatively long burning hours, incandescent lights are the dominant source. For these long burning-hour applications, the conversion from incandescent to CFL would be economical to the end-user because of the much greater energy efficiency and longer life of the CFL. Despite this apparent economic advantage for long burning-hour applications, the compact fluorescent lamp currently represents $1 \%$ of the energy use within the residence. The three reasons most frequently cited for this lack of market penetration are the high initial cost, the size and shape of the source which prohibits insertion in many sockets, and insufficient light output. The latter problem has been alleviated by the introduction of higher wattage CFLs. However, with fluorescent lamps, as wattages increase, so does the size of the lamp, further restricting the applications of the source.

To reduce the cost barrier of the CFL to the residential customer utility, programs have directly or indirectly subsidized the cost of "screw-in" compact fluorescent lamps. These programs have been less than successful in developing a continuing, sustained market for the product.

Permanently replacing incandescent lighting with more efficient light sources requires developing luminaires that are not only more efficient but also meet the same aesthetic and performance criteria of the replaced source. The luminaire must be constructed with ballast contained in the body of the fixture, which will increase the price of the product.

\section{Key Activities}

\section{Conversion of Residential Lighting to Fluorescent Sources}

Accelerating the conversion of residential lighting from primarily incandescent to efficient lighting is a goal worthy of a concerted program implemented at the state level. This conversion would consist of the following elements:

Conversion (replacement) of high-power, high-use incandescent sockets to primarily dedicated CFL fixtures. This element aims to replace high-use fixtures (including halogen torchieres) with high-efficiency, high-quality compact fluorescent fixtures tailored for the residential market. Unlike screw-based CFLs, which though accommodating the Edison socket are often subsequently replaced with inefficient incandescents after burn-out, dedicated CFL fixtures will use pin-based CF lamps that must be replaced like with like. This will ensure against "snap-back" and assures persistence of the socket conversion. The conversion of an existing socket to a dedicated CFL fixture offers the largest energy saving potential for lighting within the residential sector because CFL fixtures have much higher 
efficiencies than the incandescent fixtures that they would replace, providing up to $75 \%$ energy savings in most conversions.

Adaptation of T-8 and T-5 fluorescent lamp technology to general room lighting in residences. Several sources [Leslie and Conway 1993] have noted that the sensitive adaptation of the thinner and shorter rare-earth phosphored fluorescent lamps now common in commercial applications could stimulate a new market for small efficient fluorescent lights in many residential applications (valance lighting, bookshelf lighting, sconces, lighting for kitchen soffits). Valance lighting, for example, which can provide general lighting in many rooms of a typical home, cannot be implemented well with the bulky T-12 fluorescent lamps commonly available to homeowners.

Adaptation of commercial control products to residential market. Homeowners can currently buy many control products (such as photocell adaptors for exterior lights) that are designed to work only with incandescent loads. There are controls products that are available for controlling fluorescent lighting in commercial applications, but these have no counterpart in the residential market. (The same is true for occupant detectors.) Thus homeowners cannot inexpensively apply energy savings controls to their efficient lighting. This program element would stimulate fixture manufacturers to combine energy savings controls with efficient fixtures resulting in highly efficient products that are ready to use by the homeowner.

All of the above represent elements of a comprehensive market transformation program. Such a program might be implemented with the following five major elements:

[Siminovitch and Mills 1995]

Fostering Industry Cooperation

Creating Better Market Information

Financial Incentives and Market Pull

Professional Education and Demonstration

Institutional and Government Leadership

Although this plan was developed for implementation by the DOE at the national level, it could as well be implemented, perhaps more successfully, at the state level. Since the lighting fixture market is characterized by many small manufacturers, most of which have no R\&D resources, Lab/university partnerships that provide specialized technical assistance to selected innovative companies to successfully convert products could help jump start this industry. An excellent example is LBNL's Energy Efficient Fixtures program in which partnerships between industry and the national lab are leading to the development of new CFL-based torchieres that are much more efficient and safer than halogen torchieres.

The primary target market for the above activity is high-use sockets, i.e., those on for more than three hours per day and with higher wattage (such as torchieres). The remaining 70\% of the sockets in a typical home, which have lamps burning under two hours/day, will not tend to be replaced with CFLs since they are not cost-effective. These sockets are candidates for retrofit with the as-yet-nonexistent HIR "A" lamp discussed previously. 
By launching complementary efforts - one aimed at high-use sockets and a second aimed at "everything else" - the advanced lighting program is demonstrably integrated and coordinated, as it raises the efficiency of the main sub-markets in a building sector by fostering the use of appropriately efficient products optimized for each.

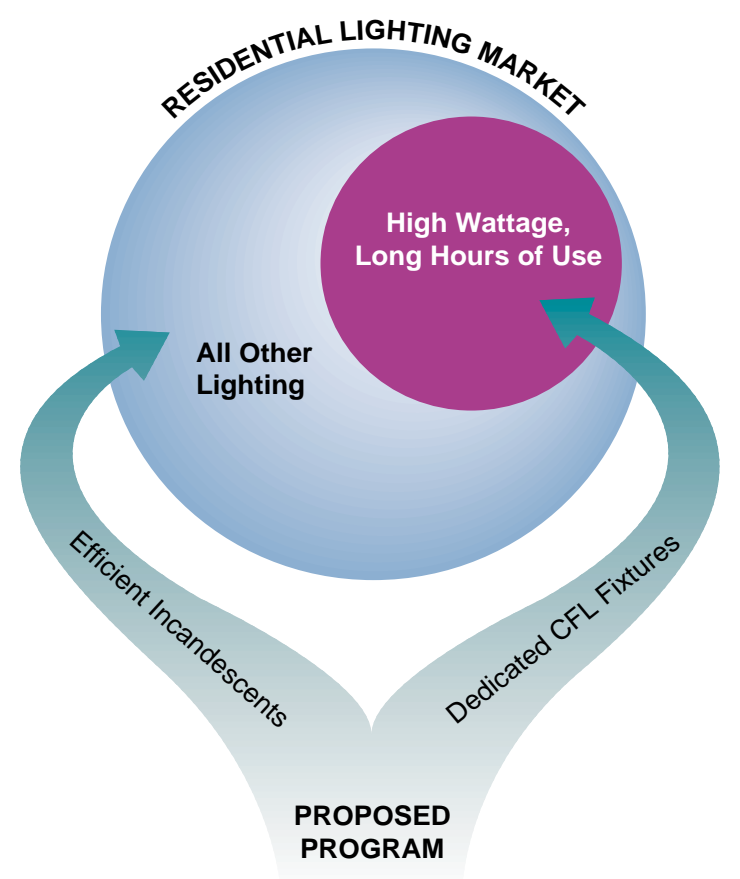

Figure 5. A pictorial representation of a two-pronged strategy to convert residential lighting to efficient lighting.

\section{Novel Task Lights for Commercial Buildings}

With downward pressure on lighting power densities (see for example the CEC's Proposed Amendment to the 1998 Energy Efficiency Standards or the national ASHRAE 90.1R), specifiers and designers are increasingly dependent on task lighting to bring light levels at primary task locations up to IES recommended levels. However, most existing task lights and furniture-mounted lighting equipment provides poor lighting quality because of poor mounting locations, inappropriate optics, and cheap components.

Using modern optics (fresnel lenses, polarizing filters, volume holographic filters, and other methods), an efficient, high quality task light (the "killer" task light) could be developed, prototyped, and demonstrated to fill this important niche market. Modern optical technology could even allow the fixture's beam spread and directionality to be tailored to occupant's needs. Such a light would use modern components (lamps, dimming electronic ballasts, accessible controls, etc.) and would require some applied optics 
research, manufacturing partnerships, and demonstration at appropriate site(s). The program could be implemented as an RFP for one or more task lighting applications with technical assistance to manufacturers supplied by National Lab and/or University. This would entail some applied research and should therefore be a candidate for PIER funding.

Low-energy ambient systems. The advanced task light discussed is only one part of an effort to bring about a reduction in building lighting power densities. For example, even if advanced task lights are generally adopted, they could simply represent an increased load unless coupled with a reduction in ambient building lighting levels (and power). Reducing the energy consumption of ambient lighting systems can be brought about by lowering ambient light levels in conjunction with improved task systems, and/or increasing the efficacy of the ambient component.

Novel ambient lighting systems could be developed by creating new fixture types based on more efficient light sources. There are three basic strategies that could be used as the basis of new ambient lighting fixtures that consume less energy than existing ambient systems. These are: (1) Fiber optics; (2) Hollow light guides; (3) Indirect lighting systems.

Each of these approaches has advantages and disadvantages as well as specific building applications where they are particularly well suited. R\&D could be applied to all of these concepts to improve the quality and energy efficiency of lighting distribution systems. Some early demonstrations of the hollow light guide design and indirect lighting systems have been conducted by LBNL over the past five years and have shown considerable promise if used in the correct applications.

Improved street lighting. Replacing HPS streetlights with metal halide sources could potentially increase visibility by using high scotopic sources for night time tasks. The main problem with this approach is that metal halide sources do not last as long as HPS lamps, making streetlights more expensive to maintain. Energy providers might favor the conversion of HPS to MH because it potentially raises lighting loads during off-peak times, thus tending to level their load profiles. However, the state's best interest is to encourage reductions in energy use regardless of the time of day.

The induction lamp announced by OSI, (or the experimental Multilux lamp from GE) combined with an advanced fixture lens that minimizes lumen depreciation, could form the basis of a new street light that would not only be much longer-lived than HPS or conventional metal halide, but would also boast low lumen depreciation. Furthermore, the spectral distribution of the lamp could be matched to whatever function modern research dictates it should be for the application and expected luminance adaptation level. This effort would require luminaire design work (integration of induction lamp with appropriate streetlight optics, low maintenance lens and photocontrols), prototype development through manufacturer partnerships, and demonstration at state agency (Caltrans, etc.) site(s). 


\section{Energy Savings Potential/State Benefit}

The average compact fluorescent lamp can reduce the energy consumption in a traditional incandescent application by approximately $75 \%$. Since $70 \%$ of residential lighting energy is consumed by just $30 \%$ of the sockets, these high-use sockets-which include surface mounts for kitchens and bathrooms, table and floor fixtures in living rooms, and exterior/outdoor fixtures-make good first targets for replacement or conversion to CFLs. Converting that $30 \%$ of sockets to dedicated CFLs would reduce our state usage by 5.5 TW-hr annually and would reduce $\mathrm{CO}_{2}$ emissions of approximately 3.6 million metric tons.

The development of better task lighting might provide the basis for considering lower lighting power densities for the ambient lighting component in non-residential buildings. The state could use its Energy Efficiency Standards (i.e., Title 24) as the mechanism for lowering the power density requirements if the technology could be developed and proven before the next revision cycle. This would lead to accelerated reductions in commercial lighting energy use with associated positive environmental effects.

Analyzing the potential energy savings from improved street lighting is difficult because it is hard to predict just how the new technology might be implemented. If research shows that "the old way" of designing street lighting systems using photopic lumens is still appropriate, then HPS would probably be replaced with metal halide on an equivalent photopic lumen basis. In this case street lighting energy consumption in California could actually increase (by up to 30\%) because metal halide is an intrinsically less efficient source of photopic lumens than the HPS system. On the other hand, if research shows that street lighting design is best performed using scotopic lumens as the key design variable (i.e., scotopic light levels would be roughly maintained when converting from HPS to metal halide), there is an energy savings potential of up to $40 \%$. In other words, the results of research that has yet to be performed will determine whether converting from HPS to metal halide is an energy saving measure or not. Since California street lighting is estimated as $1.5 \mathrm{TWh} / \mathrm{yr}$ (10\% of the $15 \mathrm{TWh} / \mathrm{yr}$ estimated for national street lighting usage), the maximum $40 \%$ energy savings potential translates to about $0.6 \mathrm{TWh} / \mathrm{yr}$. Considerable analysis would be required to ensure that such an $\mathrm{R} \& \mathrm{D}$ program resulted in a net energy savings to the state.

\section{Lighting Controls}

\section{Background and Technology Description}

Many experts believe that lighting controls are the next step in energy efficiency after installing T-8 fluorescent lamps and electronic ballasts in commercial buildings. (Most electronic ballasts today do not dim, but dimming control is more easily added to electronic ballasts than magnetic ballasts). However, unlike T-8s and electronic ballasts, which are considered reliable mainstream technologies in California, controls have not yet demonstrated that they can achieve sustainable energy savings in routine practice. Controls save energy not because they make the source more efficient but because they decrease hours of operation or dim lighting as needs change or according to the availability of daylight. At this time, controls represent a very small fraction of the market. Long-term 
studies to document the technology's savings are now underway. These studies will account for climatic differences and end-user acclimation, and will help determine the appropriate applications and relative cost of implementation and operation. These studies of lighting controls in buildings also provide critical real-world energy savings performance data to assist state regulatory agencies in deciding whether lighting controls should be adopted in future legislation.

There is significant evidence of renewed interest in lighting controls from a number of circles:

- The mandating of some lighting controls in the National ASHRAE 90.1R draft building code that is currently undergoing public review.

- The emergence of several technical committees devoted specifically to lighting controls (IESNA Computer Subcommittee, NEMA's subcommittee).

- Major ongoing demonstration of different lighting controls technologies at San Francisco Federal Building at 450 Golden Gate Ave.

- Results of a monitored installation of lighting controls at the National Center for Atmospheric Research.

- The convening of the ASERTTI/EPA/DOE Lighting Controls Roundtable at NEMA in Washington D.C. in December 1997.

Work to date has already demonstrated that photosensor response could be improved significantly. We expect that second generation sensors will combine occupancy sensors, photosensors, and manual override controls into one unit. Other technological improvements, such as more intelligent controls and remote dimming control, can be anticipated as well.

\section{Key Activities}

The state can contribute to the advancement in lighting controls and benefit from the realized energy savings and environmental benefits by funding research as well as market transformation activities in two main areas.

\section{Documentation of Energy Savings and Ancillary Benefits}

Studies of lighting controls in buildings provide critical real-world energy savings performance data to assist the state in deciding whether lighting controls should be adopted in future legislation. The advanced lighting controls testbed at the S.F. Federal Building is the first, large, carefully controlled study of the measured energy savings from lighting controls in a major office building. This study will provide much needed data to the lighting community about which lighting controls strategies work and why, and their costeffectiveness in a typical large California office building. The data from this study will begin to become available in 1998 and the CEC should consider commissioning a study to analyze this data for use as back-up material in support of potential future rulemakings. In addition to offices, there are other building types, such as retail, educational, and health care and hospitality sectors, where the energy savings potential of lighting controls needs to 
be documented if we are to convince the practicing community of the validity of lighting controls for reducing energy and maintenance costs in buildings.

New remote control technology allows building occupants to have greater control over their environmental lighting than conventional wall switches. Appropriate remote control coupled with dimmable lighting would allow occupants to control both intensity and lighting hours using a simple control similar to a familiar TV remote control. The energy savings benefits of manual dimming control and the potential ancillary benefits with regard to improved occupant satisfaction are being examined at a research campus in Colorado, but this technology has not been examined in more typical settings.

Documentation of the energy savings from controls and the building of a commission database of successful case studies is a market transformation activity that would provide needed exemplars for illustrating how the market should shift from static to dynamic lighting.

\section{More Intelligent Lighting Controls}

Previous work has indicated that photosensors need improvement if daylighting harvesting is to become a mainstream strategy. Better control algorithms need to be incorporated into ballasts and controllers and tested in the field.

A barrier to the use of controls in existing buildings is the fact that the systems are not optimized for retrofit application and are notoriously difficult to calibrate and commission after installation. A "plug-and-play" dimmable lighting system optimized for installation in existing buildings by piggybacking the control signaling on top of the in-place switch leg wiring would address these barriers. This system would only require replacing the ballasts and the switch box. This would minimize installation costs in existing buildings, therefore addressing the significant cost barrier. The system would also be factory calibrated (or self-calibrating in the field) so that it requires little or no commissioning on the installer's part. This work requires some applied research and development (about three years), industry partnerships, and market conditioning activities. It should be funded through PIER.

\section{Energy Savings Potential/State Benefit}

The commercial building sector has relatively long hours of lighting operation (average 3380 hours $^{4}$ which equates to nine hours per day). The weekly number of lighting operating hours in large offices is 81 hours, or 16 hours per weekday [Vorsatz et al 1997]. Yet most large office buildings operate with a day shift that works about 45 hours per week (nine hours times five days per work week). This suggests that there is considerable energy to be saved by reducing hours of operation to correspond more closely with the

\footnotetext{
${ }^{4}$ Calculated by taking the floorspace-weighted average for the weekly operating hours reported in Figure 2.13a of [Vorsatz 1997].
} 
actual building occupancy. Occupant- or time-based lighting controls are best suited to this task but are not commonly used in commercial buildings except in certain areas (e.g., exterior and parking lot lighting are often controlled by timeclocks or photoswitches).

To calculate the energy savings potential of lighting controls, we assume that controls can reduce the hours of operation in offices, for example, from 16 hours per weekday to 10 hours per weekday. This would result in a $37 \%$ energy savings wherever applied. Of course, this benefit might not be obtained in non-office building sectors. On the other hand, lighting controls, especially dimming controls, can do much more than reduce operating hours. Dimming lighting controls also save energy by using daylight efficiently, compensating for lumen depreciation efficiently, and tuning light levels to task. In order to obtain a rough estimate of the energy saving potential across the whole commercial building sector, we assume that lighting controls can economically save $25 \%$ of lighting energy in $50 \%$ of the commercial building floor space that uses fluorescent lighting ${ }^{5}$. The remaining floor space might not convert economically because of already short operating hours or other factors. From this assumption, we estimate that lighting controls could result in an additional energy savings of 2.4 billion $\mathrm{kW}-\mathrm{hr} / \mathrm{yr}$ in the California commercial sector after allowing for the 3 billion $\mathrm{kW}$-hr/yr reduction assumed above for converting the stock from T-12 to T-8 lamps.

\section{Lighting Systems in Buildings}

\section{Background and Technology Description}

Tomorrow's well-designed building will integrate the lighting system with the overall building energy-management system. Applied research can help implement strategies for the building lighting system beyond those of daylight harvesting or occupancy sensing discussed in the Lighting Controls section. The energy management system will integrate building lighting demands with those of other major electrical loads (HVAC, fans) to maximize efficiency and reduce operating cost. These strategies will become increasingly important with electric utility deregulation as energy providers offer electric rates that are variable in time, and building managers seek to capitalize on savings offered by these new utility pricing schemes.

Ultimately, energy management strategies for lighting in commercial spaces must be based on understanding the lighting system's performance. However, only a few select test beds are providing data in this arena. The cost of developing such test beds is so high that no one funding agency can support the effort along. GSA, PG\&E and DOE have taken the lead in developing the most extensive test bed to date at the San Francisco Federal Building. Continued funding of this research program is critical to capitalize on the full investment in the facility.

\footnotetext{
${ }^{5}$ Controls can also save energy where incandescent sources are used. HID sources can also be controlled, but in some existing stock, simple controls are already in use. To be conservative, we do not consider the energy savings obtainable by controlling incandescent or HID sources.
} 


\section{Key Activities}

\section{Intelligent Building Lighting}

Integration of intelligence into building lighting controls has enormous potential to improve building energy efficiency, lower operating costs, and potentially improve occupant comfort and satisfaction. Intelligent systems will allow:

- integration of HVAC systems and lighting systems to optimize overall building energy usage and comfort

- linkage of a building's lighting system to external real-time pricing signals from local energy providers to reduce operating costs and take maximal advantage of new pricing schemes enabled by the deregulation of the electric utility industry in California

\section{Commissioning}

The importance of proper commissioning of today's lighting controls was highlighted in a recent paper [Rubinstein 1997]. Simply summarized, commissioning is required to obtain good performance from today's lighting controls system. Yet the institutional mechanisms to assure that proper commissioning takes place are largely absent in the lighting industry. To move forward, the industry needs commissioning tools, improved specification, and installation procedures. This is both $\mathrm{R} \& \mathrm{D}$ and market transformation.

\section{LightingTools}

There is a pressing need for better lighting design tools and aids for designing and specifying energy efficient lighting solutions. The state should consider funding the development of specific tools that allow lighting designers and specifiers to more efficiently identify and specify which lighting systems are most appropriate given the specific application. Without these tools, designers have only negative incentives to attempt truly efficient designs since more efficient design takes longer and the equipment is usually more expensive. Better tools would make the energy efficient design process itself more efficient and thus increase the probability that the efficient designs would be selected over energywasteful designs. This requires some short-term R\&D and supporting market transformation activities. R\&D is needed to better integrate CAD tools with lighting design tools, to validate tools so that designers can better understand the accuracy of proposed design and avoid traditional over-design, and to allow designers to better understand both qualitative, as well as quantitative aspects of proposed design solutions.

\section{Energy Savings Potential/State Benefit}

It is difficult to estimate the potential savings from better commissioning since every building case must be individually analyzed. However, for other building systems, proper commissioning often leads to a $10 \%$ improvement in energy efficiency. It is reasonable to 
assume that the savings from proper commissioning of lighting systems will be equivalent or possibly greater.

Improved lighting design tools can probably reduce the lighting energy intensities of commercial designs by approximately $25 \%$.

\section{Human Factors}

\section{Background and Technology Description}

Since lighting is controlled by a building management system to optimize the performance of the facility, control is also available to the individual to optimize the distribution of the light in the workspace. At this time, little is known about the change in human performance as a function of access to lighting controls. Establishing this relationship could accelerate the acceptance of this technology in the marketplace. Many in the lighting industry are interested in supporting this research indirectly.

Comprehensive experiments cannot be performed in the sterile laboratory environment; they must be carried out in the workplace. Non-commercial research organizations are best used to produce results that will be accepted by end users. Before field studies are conducted, research tools for measuring performance need to be demonstrated in a controlled laboratory environment-studies focusing on the effect of spectral distribution of light in the office environment- to understand the physiology of contrast sensitivity and acuity. CEC should take an active role in establishing an industry-government research consortium on a cost-share basis.

\section{Key Activities}

\section{Quantification of Non-Energy Benefits of Energy Efficient Lighting}

It is "common knowledge" that upgrading lighting systems can lead to improved worker satisfaction with the workplace environment as well as potentially reduced absenteeism, incidence of eyestrain and/or other physical effects. Much of this information is anecdotal and cannot be extrapolated to different industries. The potential of improved productivity (or at least improved satisfaction) is often a more powerful motivator to improve and upgrade building lighting than the operating cost savings from energy reductions alone. If a stronger link could be established between improved (presumably more efficient) lighting and better productivity, this would transform the market to more efficient lighting much more rapidly than in the absence of such a proven link.

PNNL is coordinating a multi-disciplinary effort to demonstrate, through research, field measurements, and demographic studies, the ancillary benefits of energy efficient lighting and to show that quality lighting can positively affect productivity and reduce health complaints and absenteeism [Battelle 1998]. The state should consider whether it should become a supporter of this effort. 


\section{Lighting Quality Meter}

With downward pressure on lighting power densities, there will always be those who equate lower LPDs with a reduction in lighting quality. Development of a reliable measure of lighting quality is a long-term project of the IES (viz. the IESNA Quality of the Visual Environment Committee). In the interim, one could fast track a "good enough" lighting quality meter whose less ambitious purpose would be to identify bad lighting the field. We believe that sufficient knowledge is available to quickly prototype such a meter using commercially available photometers, optical filters, and baffles. It could be tested at ongoing IESNA QVE workshops as a means of verifying whether the meter's measurements correlate to experts' assessments of lighting quality in different spaces. This could be followed by field tests in different building applications in the state to demonstrate the appropriateness of this technique for identifying whether a building's lighting can be considered "acceptable".

\section{Energy Savings Potential/State Benefit}

Most of the activities discussed in this section do not save energy in and of themselves but only when coupled with regulatory or market mechanisms that take advantage of the fruits of these research activities. For instance, a lighting quality meter that is proven useful for identifying "bad" lighting could become a factor in justifying reducing Title 24 lighting power densities further than might be permissible if such a meter did not exist. Quantifying this benefit is difficult but it is not unreasonable to assume that there is some 20-25\% energy savings if these activities were aggressively implemented in the state.

\section{Education}

For the last 15 years, California has led the nation in legislating the most challenging energy efficiency standards. These standards have been moderately successful in terms of compliance [Heschong 1997] and, as a result, California buildings are more energy efficient than buildings nationwide. One reason for the success of these standards was that the CEC developed these standards through a consensus process under the guidance of the now-defunct Advanced Lighting Professional Advisory Group (ALPAG). The ALPAG, and then, later, the Lighting Efficiency Advisory Group (LEAGue), always stressed the importance of education and outreach if the lighting market was to be truly and completely transformed to efficient, quality lighting. They commissioned the Advanced Lighting Guidelines (produced in 1990 and revised in 1993), that were intended to further education and lighting information transfer. The ALGs were jointly co-funded by the CEC, DOE and EPRI under the guidance of ALPAG with the express purpose of educating specifiers by providing them with complete reliable information about the performance of advanced lighting systems. 


\section{Advanced Lighting Guidelines}

\section{Energy Efficient Lighting Information System}

The LEAGue report will identify the importance of education and lighting information transfer to furthering the goal of improving lighting energy efficiency in the state. One of the best means for the state to continue its leadership role in this area is to support a major revision of the Advanced Lighting Guidelines. The latest revision of this nationally popular document has thousands of copies in circulation and is used as major reference for Federal Energy Management training courses as well as private sector courses across the U.S.

\section{Sources}

In preparing this report, the authors have drawn on a number of sources for basic information and analysis. In particular, the reports borrow extensively from the LBNL National Lighting Strategic Plan, LBNL internal draft document. We have also used the following references:

1. Atkinson et al, Analysis of Federal Policy Options for Improving U.S. Lighting Energy Efficiency: Commercial and Residential Buildings, Lawrence Berkeley Laboratory Report LBL-31469, December 1992.

2. Energy Information Agency, Energy Consumption Series: Lighting in Commercial Buildings, March 1992.

3. Office of Building Technology, State and Community Programs, Core Databook, Version 2.1, April 1997.

4. Heschong Mahone Group, Lighting Efficiency Technology Report, Volumes 1-5, May 1997.

5. Jennings, "Residential Lighting: The Data to Date," Journal of the Illuminating Engineering Society of North America, Summer 1997.

6. Vorsatz, Shown, Koomey, Moezzi, Denver, and Atkinson, Lighting Market Sourcebook for the U.S., Lawrence Berkeley National Laboratory Report LBNL39102, December 1997.

7. Market Data from General Electric (unpublished). Communication with Robert Clear, 1997.

8. Stanford Research Institute, Business Development Strategy and Market for a New General Purpose Lamp, December 1976.

9. Energy Information Administration, Annual Energy Outlook 1997. 
10. Eto, Prahl and Schlegel, A Scoping Study on Energy-Efficiency Market Transformation by California Utility DSM Programs, Lawrence Berkeley National Laboratory Report LBNL-39058, July 1996.

11. Rubinstein et al, "On the Calibration and Commissioning of Lighting Controls," Proceedings of 4th Right Light Conference, Copenhagen, November 1997.

12. Rubinstein, Technical Specifications for an Improved Efficiency General Lighting Service Lamp, Final Report to International Energy Agency Annex III, December 1996.

13. Lighting Research Institute, "Pre-Competitive Research in the Basic Science of Commercial Light Sources to Achieve Major Breakthroughs in Performance and Efficiency," Proceedings of the 1995 ALITE Conference. LRI Report TR-106022, December 1995.

14. Siminovitch and Mills, "Dedicated Compact Fluorescent Fixtures: The Next Generation for Residential Lighting"

15. Leslie and Conway, The Lighting Pattern Book for Homes, 1993.

16. Nilsson, "Market Transformation: an Essential Condition for Sustainability," Energy for Sustainable Development, Vol. 1, No. 16, March 1995.

17. Battelle Memorial Institute, "Light Right Consortium Project: Proposal for the Lighting Industry, the Utility Industry, the Energy Service Industry, and the Federal Government of the Unites States," February 1998.

18. Conway and Boyce, "Expanding the Market for Visually Effective, Highly Efficient Exit Signs," Proceedings of 4th Right Light Conference, Copenhagen, November 1997.

19. Personal communication with Kate Conway, Lighting Research Center, November 1997.

\section{Acknowledgments}

This document was prepared with funding provided by the California Institute for Energy Efficiency. All work performed at Lawrence Berkeley National Laboratory is sponsored in part by the United States Department of Energy and is in accordance with Contract No. DEAC03-76SF000098. Publication of research results does not imply CIEE endorsement of or agreement with these findings, nor that of any CIEE sponsor.

The authors especially wish to acknowledge Jim Cole for his support of this effort. 